$\mathbb{T}$ periodica polytechnica

Mechanical Engineering

$51 / 1(2007) 15,18$

doi: 10.3311/pp.me.2007-1.02

web: http://www.pp.bme.hu/me

(C) Periodica Polytechnica 2007

RESEARCH ARTICLE

\section{Applicability of friction stir welding in polymeric materials}

\author{
Zoltán Kiss / Tibor Czigány
}

Received 2007-02-27

\begin{abstract}
The applicability of friction stir welding has been studied on polypropylene sheets. The joint strength has been analysed in terms of rotation and translation speed. It has been demonstrated that in addition to the judicious selection of welding parameters the proper construction of the welding tool is also very important. The crystallinity of the seam and its neighbourhood has been analysed by DSC, the structure of the seam border region has been analysed by optical and by scanning electron microscopy. It was found, that the seam has undergone embrittlement, as a result of non-satisfactory homogenization. Having analysed the flow circumstances during welding on seams produced by proper tool geometries it has been demonstrated that homogenization and, consequently the joint strength can be substantially improved.
\end{abstract}

\section{Keywords}

welding $\cdot$ polymers $\cdot$ material testing

\section{Acknowledgement}

The publication of the results has been supported by funds of the National Science Research Foundation (NI62729), and of the NKTH Öveges József Foundation (OMFB-01684).

\section{Zoltán Kiss}

Department of Polymer Engineering, Faculty of Mechanical Engineering, BME, H-1111 Budapest Múegyetem rkp. 3., Hungary

\section{Tibor Czigány}

Department of Polymer Engineering, Faculty of Mechanical Engineering, BME, H-1111 Budapest Múegyetem rkp. 3., Hungary

e-mail: czigany@eik.bme.hu

\section{Introduction}

Simultaneously with the increasingly dynamic development of engineering plastics the demand for rapid, reliable and high productivity welding methods (similar to those used in the case of metals) increases too [1]. Application of welding technologies is useful not only during production but also during repair or recycling, therefore new, economic, environmental-friendly technologies are being developed. Based on the method of heat introduction polymer welding technologies can be divided into three groups: methods based on heat conduction, heat radiation and mechanical friction [2]. In case of methods based on heat conduction (such as heated wedge, socket- and hot gas welding) the surfaces to be welded (in some cases also the seam material) are heated by electrically heated metal bodies, then they are pressed together to ensure the proper joint strength [3,4]. Welding methods based on irradiation (e.g. high frequency of laser welding) utilize one of the electromagnetic radiations, which, having absorbed by the material to be welded, transforms into heat, thus ensuring the proper rheological state for welding [5]. Technical basis of the friction welding methods is the heat produced by surface friction, which causes intense motion in the molecular structure of the material to be welded, therefore it gets into a state suitable for welding [6]. This family of technologies includes ultrasonic, rotation and vibration welding. A new member of this family, which appeared at the end of the 90's is friction stir welding (abbreviated as FSW) [7]. It is also based on mechanical friction, and it has already been successfully applied for light metals [8]. The method allows the manufacture of even large welded joints with high productivity, but its real advantage is its simplicity. In addition to a proper tool the only thing we need is a milling machine, and we can produce welded joints without any welding machine and even without any additional seam material (see Fig. 1).

Friction stir welding - as a method exposing the solid phase to continuous shear - exhibits certain similarity with laser, electron beam and plasma arc welding, as the so-called "keyhole effect" also appears along the moving heat source. This phenomenon is related to the "empty" space (similar to a keyhole) formed immediately behind the moving, point-like heat source, 


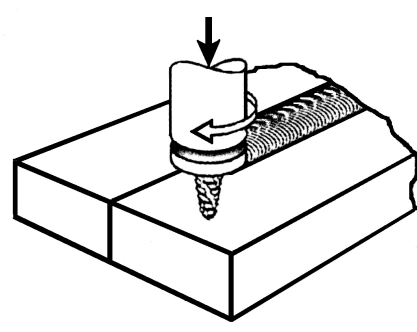

Fig. 1. Schematic presentation of friction stir welding.

behind which the melt fronts, passing the heat source, unite. The material and construction of the welding tool is essential to ensure the solidification process around the "keyhole", which in turn determines the quality of the welded joint. The basis of the tool is the collet front face and shank. The collet front face presses to the part to be welded and controls the plastic welding zone. Because of the friction between the collet front face and the welded part heat is formed, which is the main heat source when welding thin sheets. If the thickness of the welded part increases, the shank exposed to friction has to transport more heat into the welded part. The main function of the shank is to shape the material along the seam line, and to control the flow of the material around the shank and below the collet front face, to ensure proper welding. Different constructions are needed for butt joints and for overlapping joints, as the geometrical properties together increase the ratio of static and stirred volumes characteristic of the tool, and help the flow of the plastic material under the tool.

The main goals of this article include the study of conditions and possibilities of the application of friction stir welding for various polymeric materials, the design the proper welding tool geometry, the investigation of physical processes occurring during the welding process and the analysis of the strength properties of the welded joints.

\section{Materials and Methods}

Friction stir welding experiments were performed on a universal milling machine with various milling tools. Based on our preliminary experiments the effect of rotation and translation speed, as well as that of the tool geometry was studied on the strength of the welded joint. It has been demonstrated that the tool geometry has the strongest effect. Similarly to aluminum one or more grooves are needed, which, instead of accumulation collect the material behind the tool [9]. It is important to prepare a collet front face of proper size, which ensures that the material stays within the welding groove. Based on all these the tool used was a commercially available, traditional milling tool with $8 \mathrm{~mm}$ diameter, containing 6 grooves, with $30^{\circ}$ groove slope. Welding was performed with $400 \mathrm{~mm} / \mathrm{min}$ translation speed and $6301 / \mathrm{min}$ rotation speed using a rotation direction opposite to the milling direction to avoid the milling of the raw material but to promote mixing. The collet used to fix the milling tool to the milling machine was used as a fixing front face. The parts to be welded were $15 \mathrm{~mm}$ thick PP-WDU (MFI=0,5795 g/10 min) sheets extruded on a SIMONA extruder.

Tensile tests were performed on a ZWICK Z020 universal tensile tester, using $20 \times 150 \mathrm{~mm}$ specimens at a tensile rate of $10 \mathrm{~mm} / \mathrm{min}$, at ambient temperature. Tensile strength was the average of five parallel tests. DSC tests to determine the crystallinity were performed on a Perkin-Elmer differential scanning calorimeter, at a heating rate of $10 \mathrm{~K} / \mathrm{min}$, in the temperature range of 350-500 K. Seams and fracture surfaces were analysed by an OLYMPUS BX51M optical microscope and by a JEOL JSM 6380LA scanning electron microscope.

\section{Results and Discussion}

Based on the tensile tests performed on specimens cut from the welded sheets it has been concluded that the welded parts behaved in a much more brittle manner than the matrix material. The tensile strength was $11.5 \mathrm{MPa}$, which corresponds only to about $50 \%$ of the original value. In spite of this meager result the test proved that the method can be successfully applied also for polymer structural materials. In order to analyse the thermal conditions during the welding process and to determine the crystallinity of the seam formed DSC tests were made on samples taken from the matrix, from the seam and from the two sides of the border line between the matrix and the seam. Average heats of fusion are shown in Fig. 2. Based on the column dia-

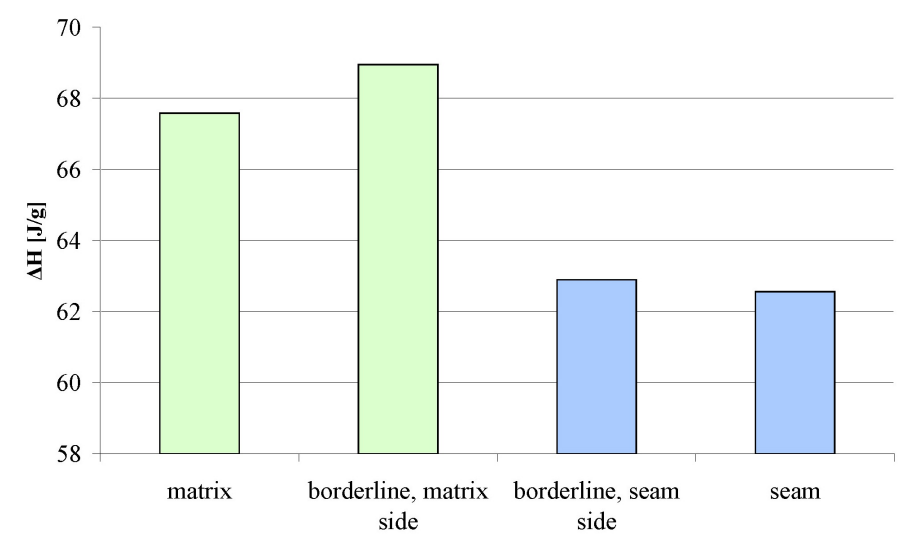

Fig. 2. Comparison of the heats of fusion measured by DSC.

grams it can be concluded that the crystallinity is reduced in the seam, what means that the amorphous content is higher in the seam than in the matrix. The reason for this is that the metal tool which is large in size as compared to the seam absorbs rapidly the heat from the seam, which results in rapid cooling and in reduced crystallinity. The molten material located at the largest distance from the tool can be found at the matrix side of the seam border, which has more time for cooling, therefore the crystallinity is the largest there.

The brittle behaviour of the welded seam results in a less than necessary cohesive strength at the interface between the matrix and the seam, what characterizes the quality of the welding. On 
Fig. 3 a well discernible borderline can be seen along the seam border, indicating the lack of cohesive contacts. The difference between the inhomogeneity of the seam on the left hand side and the relatively uniform fracture surface of the matrix on the right hand side supports the observations of the DCS measurements, according to which there is a crystallinity difference between the matrix and the seam. When approaching from the matrix fracture surface a significant embrittlement can be observed.

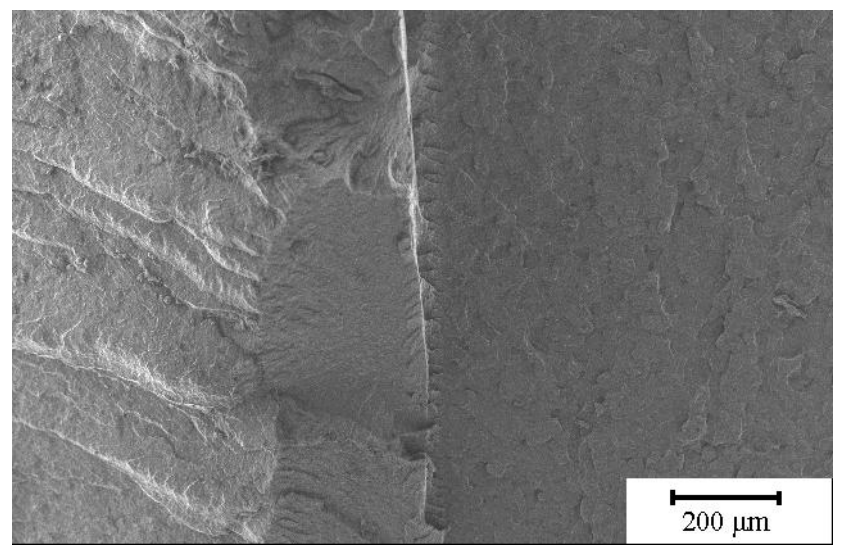

Fig. 3. Scanning electron micrograph of the fracture surface of the welded seam.

The precondition for the formation of a stronger seam is the optimal choice of welding parameters, it is also necessary to use optimal tool geometry. The tool simultaneously has to heat up the material by friction and to bring it into a swirling motion to ensure homogenization. Additionally it has to develop the seam. The number and shape of the grooves on the head protruding in-between the parts to be welded have to be selected properly to ensure the transport of the melt to the opposite side of the progressing tool, to the back side of the head. By changing the cross section and the slope of the grooves the necessary mixing-shearing effect can be enhanced in the molten material. The necessity of the presence of grooves is clear, nevertheless this requirement has to be reconciled with the natural requirement to increase the friction surface, as it increases the heat provided. The most obvious way to increase the surface of a body with nearly constant volume is to produce ribs or grooves on the surface, the orientation of which has to be adjusted to the flow conditions. It is known that high molecular polymer melts behave differently from low molecular fluids, which is a rehological problem. It is sure anyway that the flow conditions influence significantly the quality of the welded joint. Therefore we continued our experiments with two milling tools produced by Vil-Tools Ltd, containing 8 grooves with 15 and $45^{\circ}$ groove slopes respectively (see Fig. 4).

Parameters used during welding are summarized in Table 1 It can be seen that altogether 20 combinations were used, 40 for the two tools.

The results of the tensile tests performed on specimens cut from the welded sheets prepared by tools with a groove slope of 15 and $45^{\circ}$ are shown in Figs 5 and 6 respectively.

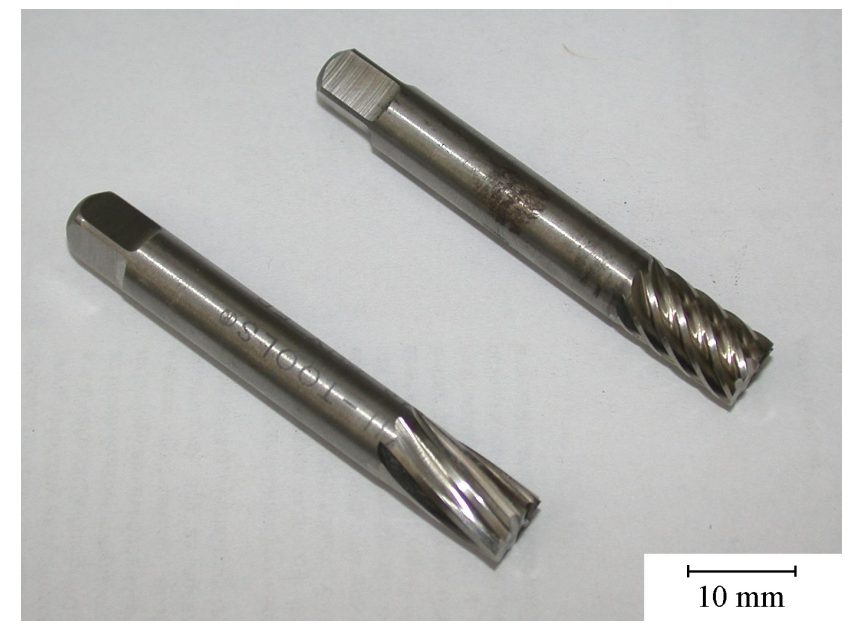

Fig. 4. Milling tools with $15^{\circ}$ and $45^{\circ}$ groove slope.

Tab. 1. Parameter settings used during the welding experiments

\begin{tabular}{llllcc}
\hline Parameter & \multicolumn{5}{c}{ Values } \\
\hline Rotation speed (1/min) & 450 & 630 & 900 & 1250 & 1800 \\
Translation speed (mm/min) & 20 & 31.5 & 40 & 63 \\
\hline
\end{tabular}

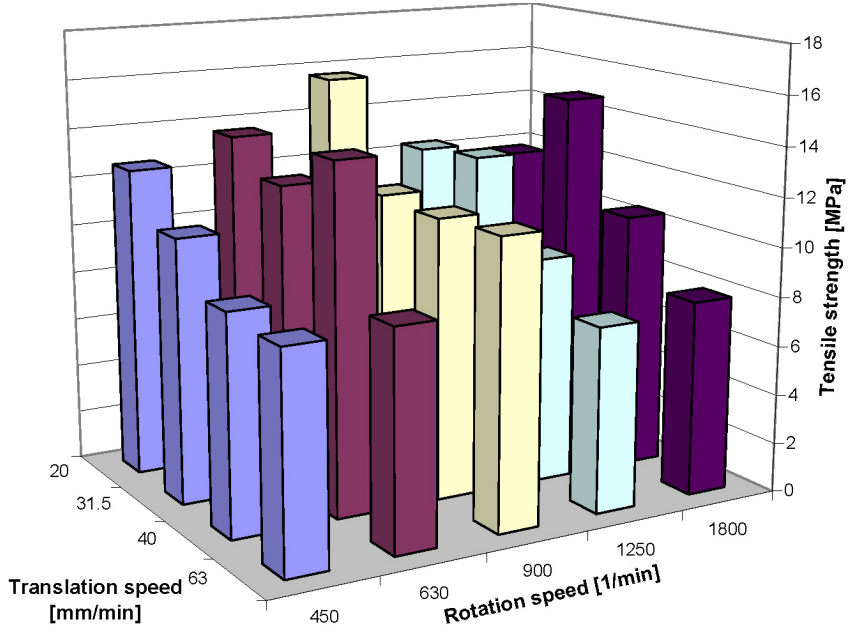

Fig. 5. Tensile strength values of welded joints prepared by $15^{\circ}$ tool

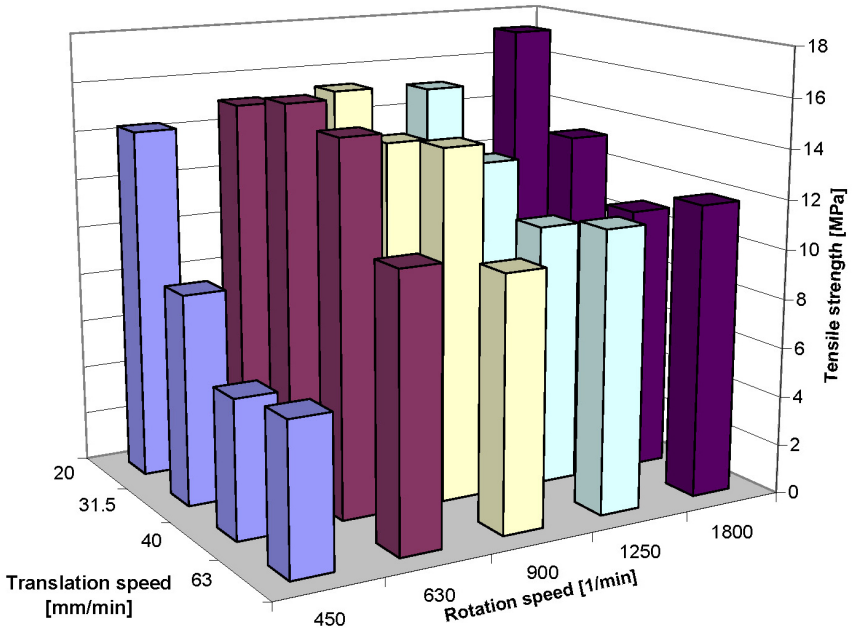

Fig. 6. Tensile strength values of welded joints prepared by $45^{\circ}$ tool. 
It can be observed that the measured values are much higher than the tensile strengths observed in the preliminary experiments. It can also be observed that the welded joints prepared by the tool with $15^{\circ}$ slope are usually weaker than the ones prepared by the $45^{\circ}$ tool. It can be concluded that the more frequent grooves are advantageous for the better weld seam quality. It can be observed in both cases that the tools react to changes in the welding parameters similarly. An increase of the rotation speed improves the strength of the joint as does the reduction of the translation speed. It can be explained by the fact that in case of slower translation speed the tool has more time heat up the material, and higher rotation speed also results in higher heating effect. The specific energy absorbed by a unit length of the welded seam is linearly proportional to the rotation speed and inversely proportional to the translation speed. In the case of friction stir welding heating, homogenization, pressing occur simultaneously, followed by cooling when the tool passes by, therefore it is important to find out the degree of homogenization. Therefore flow conditions, which directly influence the weld quality, were studied. In order to study these conditions optically, sheets of different colours were used. Blue and grey sheets were used in our experiments, in which welded joints were prepared with the 15 and $45^{\circ}$ milling tools, using the optimum parameters found previously and finally polished sections were prepared perpendicularly to the longitudinal axis of the welded joint. While the two colours visibly separated in the case of the $15^{\circ}$ tool, a good "intermeshing" of the two materials could be observed in the case of the $45^{\circ}$ tool (see Fig. 7). It means that the two materials penetrate each other in a laminar arrangement, and they are distributed homogeneously according to the rotation of the milling tool.

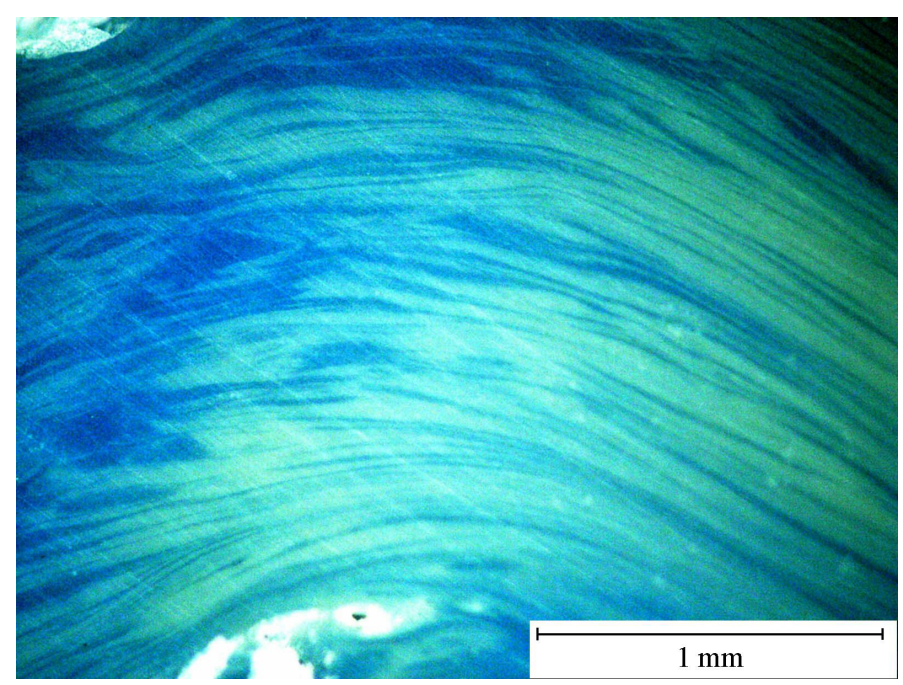

Fig. 7. Polished section made perpendicularly to the seam prepared by the $45^{\circ}$ tool.

\section{Conclusions}

The applicability of friction stir welding (FSW) to polymeric materials was proved by welding polypropylene sheets. Seams were prepared using various welding parameters and their prop- erties were studied using tensile, DCS, optical and scanning electron microscopy. Flow conditions during welding were also investigated. It was proved that the FSW technology can be applied under practical conditions, but the optimization of technology parameters and the tool geometry still need much improvement. It was demonstrated that a denser groove distribution gives better results under identical welding conditions than a tool with lower groove slope. It was also demonstrated that one or more grooves are needed to collect the material behind the tool instead of accumulating it. It is also necessary to make a front face of proper size to ensure that the material remains in the welding groove.

\section{References}

1 Kalpakjian S, S.R. Schmid SR, Manufacturing process for engineering materials, Prentice Hall, New York, 2003.

2 Grewell DA, Benatar A, Park JB, Plastics and composites welding handbook, Carl Hanser Verlag, München, 2003.

3 Marczis B, Czigány T, Interrelationships between welding parameters of hot-gas welded polypropylene, Polymer Engineering and Science 46 (2006), 1173-1181.

4 , Microstructure of the heat affect zone of hot-gas welded polypropylene, International Polymer Processing 21 (2006), 141-148.

5 Bonten C, Tüchtert C, Welding of plastics - Introduction into heating by radiation, Journal of Reinforced Plastic and Composites 21 (1998), 699-709.

6 Crawford RJ, Tam Y, Friction welding of plastics, Journal of Materials Science 16 (1981), 3275-3282.

7 Thomas WM, Andrews RE, High performance tools for friction stir welding (FSW), 1999. International Patent Application WO 99/52669.

8 Mishra RS, Ma ZY, Friction stir welding and processing, Materials Science and Engineering 50 (2005), 1-78.

9 W.M. Thomas WM, Nicholas ED, Smith SD, Friction stir welding- tool developments, New Orleans, 2001. Aluminum Joining Symposium. 